\title{
The Primary Care Performance of Three Types of Medical Institutions: A Public Survey using the Korean Primary Care Assessment Tool
}

\author{
Hye-Min Jung ${ }^{1, \pi}$, Min-Woo Jo ${ }^{2, \pi}$, Hyun-Joo Kim³, Won-Mo Jang ${ }^{4}$, Jin-Yong Lee ${ }^{1,5,{ }^{*}}$, Sang-Jun Eun ${ }^{6, *}$ \\ 'Department of Health Policy and Management, Seoul National University College of Medicine, Seoul, Korea \\ ${ }^{2}$ Department of Preventive Medicine, University of Ulsan College of Medicine, Seoul, Korea \\ ${ }^{3}$ Department of Nursing Science, Shinsung University, Dangjin, Korea \\ ${ }^{4}$ Health Review and Assessment Committee, Health Insurance Review and Assessment Service, Wonju, Korea \\ ${ }^{5}$ Department of Public Health and Community Medicine, Seoul Metropolitan Government - Seoul National University Boramae \\ Medical Center, Seoul, Korea \\ ${ }^{6}$ Department of Preventive Medicine, Chungnam National University School of Medicine, Daejeon, Korea \\ IThese authors contributed equally this work. \\ *These authors also contributed equally to this work.
}

Purpose: The healthcare system of South Korea is at the extreme of the dispersed system. Few regulations limit patients from directly visiting higher-level medical institutions for primary care sensitive conditions. As a result, similar to local clinics, general and tertiary teaching hospitals also provide diverse primary care services. Our study aimed to examine the general public's perceptions of their primary care performance.

Methods: Face-to-face surveys were conducted with 1000 adults who were living in South Korea with the aid of a questionnaire that included the Korean Primary Care Assessment Tool (KPCAT). The KPCAT consists of five domains, which are the main indicators of primary care performance: first contact, comprehensiveness, coordination, personalized care, and family/community orientation. One-way analysis of variance and post hoc tests were used to compare the KPCAT scores across the three types of medical institutions.

Results: Domain-wise analyses revealed two different patterns. With regard to first contact and its subdomains, the highest and lowest scores emerged for local clinics and tertiary teaching hospitals, respectively. However, the other four domain scores were significantly lower for local clinics than for the other two types of medical institutions.

Conclusions: Local clinics were perceived to be medical institutions that are responsible for providing primary care. However, the general public perceived only one domain of their primary care to be superior to that of the other two types of medical institutions: first contact. National efforts should be taken to strengthen their other four domains of primary care by training their workforce and providing appropriate incentives.

Key words: Primary healthcare, Healthcare quality assessment, Cross-sectional survey, Health facilities, South Korea

Received: Sep.08.2019 Revised: Oct.04.2019 Accepted: Oct.16.2019

Correspondence: Jin-Yong Lee

Department of Public Health and Community Medicine, Seoul Metropolitan Government - Seoul National University

Boramae Medical Center, Seoul 07061, Korea. Tel: +82-2-870-2165 E-mail: jylee2000dgmail.com

Correspondence: Sang-Jun Eun

Department of Preventive Medicine, Chungnam National University School of Medicine, Daejeon 35015, Korea.

Tel: +82-42-580-8262 E-mail: jylee2000dgmail.com

Funding: None Conflict of Interest: None

Quality Improvement in Health Care vol.25 no.2

(C) The Author 2019. Published by Korean Society for Quality in Health Care; all rights reserved

16 Quality Improvement in Health Care 


\section{Introduction}

Since Lord Dawson established the concept of the organized healthcare system in 1920, there have been two different approaches to organizing primary, secondary, and tertiary care within the healthcare system. The first approach is a highly structured and regionalized system, which is mainly adopted in Northern European countries, including the United Kingdom [1]. Medical institutions in this system provide services that represent a specific level of healthcare. Furthermore, their location within an area is carefully chosen according to the distribution of patients. In general, local clinics that are operated by a general physician provide primary care, general hospitals provide secondary care, and tertiary hospitals provide tertiary care. Patients who visit local clinics are usually referred to a higher-level medical institution until they reach the "right place" that can provide them with the appropriate care that they require, irrespective of their preferences. On the other hand, many other countries, including the United States, have adopted a dispersed model of care, which allows patients to visit specialists or higher-level medical institutions without a primary physician's recommendation [1]. This system is frequently criticized because it results in high costs and a waste of resources. However, it can maximize the convenience of patients who wish to quickly address their health problems [2-4].

The South Korean healthcare system is often perceived to have adopted an extreme version of the dispersed model of care. Despite the universal healthcare coverage that is provided by the National Health Insurance Program, there are a few reg- ulations that restrict patients from directly visiting a hospital without a referral [5-6]. Moreover, South Koreans generally prefer hospitals to local clinics because they believe that the quality of care that is provided by hospitals is better than that of local clinics, even with regard to basic care [7-8]. As a result, patients who require only basic outpatient care also visit hospitals; thus, a large proportion of the outpatient services of hospitals are devoted to primary care [9]. It has recently been reported that many other countries are facing a similar situation and struggling to find a way to ease the herd behaviors of their patients [10-14].

The definition and attributes of primary care have been discussed for a long time [15-17]. In sum, primary care is a forefront point of the healthcare system, Typically, it privides care to individuals with common illnesses such as the common cold (first sontact). Further, it provides preventive services to the entire community and helps patients with chronic diseases manage their condition (i.e., comprehensiveness). Primary care providers also refer patients who require further evaluation or treatment to higher-level medical institutions (i.e., coordination) and for follow-up care (i.e., continuity). In addition to these traditional "gatekeeping" functions, primary care recently has expanded its boundaries to incorporating various healthcare services $[2,18]$. It is well known that the provision of better primary care within a healthcare system is associated with better overall healthcare quality and lower healthcare costs [19-20]. As medical practices become more complex and fragmented, the importance of primary care is being increasingly emphasized. In this regard, the Korean healthcare system cannot sustain without establish- 
ing and reinforcing its primary care services.

Some changes to the healthcare system are imperative to strengthening primary care in South Korea, and the support of the general public is also essential to a smooth transition to the new system. For example, in France, the "preferred doctor scheme" was more easily accepted by a majority of those who already had a regular family doctor before the system was launched [10]. Therefore, understanding the general public's experiences of primary care will play a helpful role in identifying which aspects of primary care should be further strengthened. In this manner, this study aimed to investigate the general public's perspectives on the primary care services that were provided by local clinics and general and tertiary hospitals.

\section{Methods}

We aimed to recruit a sample that was representative of the population of adults in South Korea. We used quota sampling because it is not only time- and cost-effective but can also provide the equivalent result compared to probability one [2122]. The number of participants who belonged to each stratum was ascertained based on the sample size and the proportion of the population that was constituted by those who belonged to a given stratum [23]. In this study, age, sex, and residence were used as the strata, and the proportion of the strata was calculated based on the 2014 Population Census that was undertaken by Statistics Korea. A total of 1000 adults who were older than 18 years and were living in six major cities in South Korea (i.e., Seoul, Busan, Daegu, Incheon, Kwangju, Daejeon, and Ulsan) were recruited in this study, irrespective of their past experience of visiting medical institutions. The sampling error was $\pm 3.1 \%$ at the $95 \%$ confidence level.

Professional interviewers, who had been trained by the research agency, Gallup Korea, conducted face-to-face interviews with members of the general public. Individual interviews were conducted using a computer-assisted questionnaire that had been developed for the general public. The responses were reviewed by supervisors for quality control. If there were errors in recording even one response, the entire interview data of the respective participant was discarded, and a new participant was recruited and interviewed. The questionnaire required participants to provide the following information: age, sex, residence, educational level, self-reported socioeconomic status, presence of chronic diseases, frequency of visits to medical institutions, and their assessment of the primary care performance of the three types of medical institutions (order: local clinics, general hospitals, and tertiary hospitals).

The Korean Primary Care Assessment Tool (KPCAT), which has been developed by Lee et al., was used to quantify participants' assessments of primary care performance in an objective manner [24]. The subject and object of each KPCAT question were changed from "this" to "local clinic," "general hospital," or "tertiary hospital" in order to assess the primary care performance of the three different types of medical institutions. All the modified questions of the KPCAT are presented in table 1. The 21 questions of this assessment are classified into five domains: first contact, comprehensiveness, coordination, personalized care, and family/ community orientation. First contact was the only 
composite domain that consisted of five subdomains, each of which was assessed by a single item. The other domains consisted of three to five items. Our participants were required to record their response to each question on a 5-point Likert scale $(1=$ strongly disagree, $2=$ disagree, $3=$ neutral, 4 = agree, 5 = strongly agree). A "don't know" option was also presented, and it was assigned a score of 3 during data analysis. In accordance with the scale developer's recommendation, the 5-point Likert scale was converted into a grading scale that ranged from 0 to 100 to enhance the ease of inter- pretation [24]. For each domain, the final score was computed by averaging the individual item or subdomain scores. One-way analysis of variance and Scheffe's post hoc test were used to compare the domain and subdomain scores across the different types of medical institutions. All statistical analyses were conducted using SAS Enterprise Guide 7.1 and $p$-value over 0.01 was considered significant.

This study was approved by the institutional review board (IRB) of Chungnam National University School of Medicine (IRB No.14-02).

Table 1 . Korean primary care assessment tool

\begin{tabular}{|c|c|}
\hline Domains (number of items) & Questionnaire items \\
\hline \multicolumn{2}{|l|}{ First contact (5) } \\
\hline First contact utilization & I will visit (LC/GH/TH) first when a new health problem arises. \\
\hline Facility accessibility & It is easy to access (LC/GH/TH) geographically, temporally and economically. \\
\hline Cost appropriateness & Out-of-pocket cost is appropriate. \\
\hline Demographic accessibility & (LC/GH/TH) sees patients regardless of their age and sex. \\
\hline Basic health care & I will visit (LC/GH/TH) first when I need basic health care like dressing, suture, or splint. \\
\hline \multirow[t]{4}{*}{ Comprehensiveness (4) } & I will visit (LC/GH/TH) when I need medical check-up like blood pressure. \\
\hline & I will visit (LC/GH/TH) when I need counsels for cancer prevention and screening. \\
\hline & I (or my family member) will get periodic Pap smear tests at (LC/GH/TH). \\
\hline & I will get periodic health examination at (LC/GH/TH). \\
\hline \multirow[t]{3}{*}{ Coordination (3) } & (LC/GH/TH) recommend health care resources appropriately. \\
\hline & (LC/GH/TH) recommend another doctor I need to visit appropriately. \\
\hline & (LC/GH/TH) review the referral results. \\
\hline \multirow[t]{5}{*}{ Personalized care (5) } & (LC/GH/TH) treat mental health problems as well as physical health problems. \\
\hline & (LC/GH/TH) understands patients' words easily. \\
\hline & (LC/GH/TH) explains test results to the patient easily. \\
\hline & (LC/GH/TH) is well aware of the importance of the patients' medical history. \\
\hline & I trust (LC/GH/TH)'s decisions on diagnosis and treatment. \\
\hline \multirow[t]{4}{*}{ Family and community orientation (4) } & (LC/GH/TH) concerns about my family and living environment. \\
\hline & (LC/GH/TH) knows about the health, well-being and environmental problems of my community. \\
\hline & (LC/GH/TH) is active in promoting the health of my community. \\
\hline & (LC/GH/TH) surveys and reflects people's opinions on health care. \\
\hline
\end{tabular}

Note. LC, local clinic; GH, general hospital; TH, teaching hospital 


\section{Results}

Table 2 presents the general characteristics of the participants and the total KPCAT scores for the three types of medical institutions. The sex ratio was exactly $1: 1$, and the forties were the majority $(23.2 \%)$. Almost half of the participants (43.9\%) were residing in the capital city of South Korea (i.e., Seoul). The distribution of these three characteristics reflected that of the whole population in South Korea. Most of the participants reported that they belonged to a middle (55.9\%) or low (34.7\%) socioeconomic status. With regard to education- al level, a majority of them had at least graduated from high school (i.e., graduated from high school: $45 \%$, above university: $50.9 \%$ ). Only $10.7 \%$ of them had chronic diseases, and $20.4 \%$ of them had family members with chronic diseases. All participants except a meager $1 \%$ had frequently visited medical institutions, and a majority (85.5\%) of them reported that they had visited local clinics for simple health problems. There was no significant demographic difference in participants' total scores on the KPCAT. However, participants who lived in Incheon and Daejeon provided relatively lower scores than others did.

Table 2. General characteristics of the respondents and KPCAT total score

\begin{tabular}{|c|c|c|c|c|c|c|c|c|c|}
\hline \multirow[t]{2}{*}{ Variables } & \multirow[t]{2}{*}{ Category } & \multirow[t]{2}{*}{$\mathrm{N}$} & \multirow[t]{2}{*}{$\%$} & \multicolumn{6}{|c|}{ KPCAT total score } \\
\hline & & & & Mean & S.D. & Mean & S.D. & Mean & S.D. \\
\hline Total & 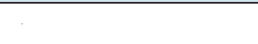 & 1000 & 100.0 & 61.0 & 11.4 & 61.0 & 11.1 & 59.4 & 12.4 \\
\hline \multirow{2}{*}{ Sex } & Male & 500 & 50.0 & 61.1 & 10.9 & 61.0 & 11.0 & 59.4 & 12.5 \\
\hline & Female & 500 & 50.0 & 60.8 & 11.9 & 61.1 & 11.2 & 59.4 & 12.2 \\
\hline \multirow{5}{*}{ Age } & 19 29 & 190 & 19.0 & 61.9 & 10.4 & 61.0 & 10.1 & 60.1 & 12.7 \\
\hline & $30 \sim 39$ & 212 & 21.2 & 59.6 & 11.3 & 60.3 & 11.1 & 58.8 & 11.8 \\
\hline & $40 \sim 49$ & 232 & 23.2 & 60.5 & 12.2 & 62.0 & 11.5 & 59.6 & 12.9 \\
\hline & $50 \sim 59$ & 224 & 22.4 & 61.4 & 11.3 & 60.5 & 11.6 & 59.2 & 12.0 \\
\hline & over 60 & 142 & 14.2 & 61.9 & 11.8 & 61.7 & 10.9 & 59.3 & 12.5 \\
\hline \multirow{6}{*}{ Residence } & Seoul & 439 & 43.9 & 62.1 & 10.2 & 62.3 & 9.9 & 60.2 & 12.1 \\
\hline & Busan & 153 & 15.3 & 59.7 & 11.1 & 60.4 & 10.6 & 59.2 & 11.8 \\
\hline & Daegu & 106 & 10.6 & 63.1 & 12.1 & 61.8 & 12.4 & 55.6 & 15.0 \\
\hline & Incheon & 125 & 12.5 & 56.4 & 14.1 & 56.1 & 11.5 & 59.3 & 13.0 \\
\hline & Daejeon & 65 & 6.5 & 56.8 & 9.9 & 55.1 & 11.7 & 57.3 & 11.3 \\
\hline & Ulsan & 50 & 5.0 & 61.9 & 8.4 & 65.3 & 9.7 & 61.9 & 11.5 \\
\hline \multirow{4}{*}{$\begin{array}{l}\text { Standards of living } \\
\text { (self-reported) }\end{array}$} & High & 84 & 8.4 & 59.4 & 11.6 & 60.3 & 10.9 & 61.3 & 10.8 \\
\hline & Middle & 559 & 55.9 & 61.9 & 11.0 & 61.8 & 11.1 & 60.0 & 12.6 \\
\hline & Low & 347 & 34.7 & 60.0 & 11.8 & 60.2 & 11.2 & 58.0 & 12.2 \\
\hline & Refuse to reply & 10 & 1.0 & 56.2 & 15.4 & 55.6 & 9.5 & 56.2 & 12.9 \\
\hline \multirow[t]{3}{*}{ Education } & Under middle school & 41 & 4.1 & 62.3 & 12.2 & 63.7 & 11.7 & 62.0 & 12.4 \\
\hline & High school & 450 & 45.0 & 62.1 & 11.3 & 61.1 & 11.1 & 59.2 & 12.0 \\
\hline & Above university & 509 & 50.9 & 59.9 & 11.4 & 60.8 & 11.1 & 59.3 & 12.7 \\
\hline \multirow{2}{*}{$\begin{array}{l}\text { Chronic disease } \\
\text { (self) }\end{array}$} & Yes & 107 & 10.7 & 61.1 & 11.3 & 61.1 & 10.5 & 58.7 & 11.2 \\
\hline & No & 893 & 89.3 & 61.0 & 11.4 & 61.0 & 11.2 & 59.5 & 12.5 \\
\hline \multirow{5}{*}{$\begin{array}{l}\text { Chronic disease } \\
\text { (family) } \\
\text { Frequently visiting } \\
\text { medical institution }\end{array}$} & Yes & 204 & 20.4 & 60.4 & 11.9 & 60.1 & 11.6 & 58.9 & 12.6 \\
\hline & No & 796 & 79.6 & 61.1 & 11.3 & 61.3 & 11.0 & 59.5 & 12.3 \\
\hline & Local clinic & 853 & 85.3 & 61.9 & 10.9 & 61.1 & 11.2 & 59.2 & 12.4 \\
\hline & Others & 27 & 2.7 & 58.6 & 13.7 & 58.9 & 12.2 & 57.4 & 13.8 \\
\hline & None & 10 & 1.0 & 52.6 & 10.2 & 57.4 & 7.7 & 57.5 & 11.7 \\
\hline
\end{tabular}

Note. KPCAT, Korean Primary Care Assessment Tool; S.D., standard deviation 
Table 3 presents the KPCAT scores (i.e., total, domain, and subdomain scores) that emerged for local clinics and general and tertiary hospitals. With regard to the total score, a significantly lower score emerged for tertiary hospitals (59.38) than for local clinics (60.97) and general hospitals (61.05). However, the domain-specific results were very heterogeneous. Among five domains, local clinic got the highest score in "first contact" (73.84), general hospital in "comprehensiveness" (63.37), and tertiary hospital in "personalized care" (65.11). When domain scores were compared across the three institutions, the highest scores on the first contact domain and its subdomains emerged for general hospitals (73.84) and the lowest scores emerged for tertiary hospitals (59.38). Scores on the comprehensiveness domain were significantly lower for local clinics (55.85) than for the other two types of institutions, but there was no significant differ- ence between general (63.37) and tertiary (61.81) hospitals. Scores on the coordination domain were also the lowest for local clinics (59.88) and highest for tertiary hospitals (62.43), but it was hard to say there was a clear-cut point. Scores on the personalized care domain were significantly higher (and the highest) for tertiary hospitals (65.11), but there was no significant difference between local clinics (62.69) and general hospitals (62.75). Finally, significantly lower (and the lowest) scores (52.61) on the family/community orientation domain emerged for local clinics; similar scores emerged for the other two types of institutions (general hospitals: 54.71, tertiary hospitals: 55.98). This section should be divided into sections using subheadings. It should provide a concise and precise description of the experimental results, their interpretation, and experimental conclusions that can be drawn based on the findings.

Table 3. KPCAT scores of the three types of medical institution by domain and subdomain $(n=1,000)$

\begin{tabular}{|c|c|c|c|c|c|c|c|c|c|}
\hline \multirow{2}{*}{ Domains of KPCAT } & \multicolumn{2}{|c|}{ Local clinic } & \multicolumn{2}{|c|}{ General hospital } & \multicolumn{2}{|c|}{ Teaching hospital } & \multirow{2}{*}{$\mathrm{F}^{\dagger}$} & \multirow{2}{*}{$p$-value } & \multirow{2}{*}{ Scheffe ${ }^{\dagger}$} \\
\hline & Mean & S.D. & Mean & S.D. & Mean & S.D. & & & \\
\hline Total score & 60.97 & 11.43 & 61.05 & 11.11 & 59.38 & 12.37 & 6.53 & .0015 & $c<a \cdot b$ \\
\hline First contact & 73.84 & 13.01 & 63.30 & 12.72 & 51.60 & 16.32 & 621.13 & $<.0001$ & $c<b<a$ \\
\hline First contact utilization & 70.73 & 19.37 & 60.15 & 18.54 & 50.88 & 25.33 & 217.52 & $<.0001$ & $c<b<a$ \\
\hline Facility accessibility & 79.93 & 19.12 & 63.18 & 20.00 & 45.88 & 25.80 & 607.73 & $\langle .0001$ & $c<b<a$ \\
\hline Cost appropriateness & 69.73 & 18.39 & 55.78 & 20.80 & 39.83 & 23.85 & 501.22 & $\langle .0001$ & $c<b<a$ \\
\hline Demographic accessibility & 78.63 & 19.92 & 74.85 & 18.17 & 72.35 & 21.70 & 24.99 & $\langle .0001$ & $c<b<a$ \\
\hline Basic health care & 70.18 & 20.71 & 62.55 & 20.23 & 49.08 & 25.97 & 226.44 & $\langle .0001$ & $c<b<a$ \\
\hline Comprehensiveness & 55.85 & 17.41 & 63.37 & 15.78 & 61.81 & 18.55 & 52.69 & $\langle .0001$ & $a<c . b$ \\
\hline Coordination & 59.88 & 16.47 & 61.12 & 15.35 & 62.43 & 16.18 & 6.31 & .0018 & a.b $<$ b.c \\
\hline Personalized care & 62.69 & 14.24 & 62.75 & 13.46 & 65.11 & 15.30 & 9.22 & .0001 & a.b $b c$ \\
\hline Family and community orientation & 52.61 & 16.60 & 54.71 & 15.53 & 55.98 & 16.96 & 10.76 & $\langle .0001$ & $a<b . c$ \\
\hline
\end{tabular}

Note. KPCAT, Korean Primary Care Assessment Tool; S.D., standard deviation

†F-statistics of one-way ANOVA

† Scheffe post-hoc test. 


\section{Discussion}

It has only been twelve years since the Korean version of primary care concept was established. Therefore, both doctors and patients are still unfamiliar with this concept [7,25]. Gatekeeping role of the primary physician is ambiguous because the specialist can run the outpatient clinic as well as there is no limitation on local clinic having high-level equipment and facilities [6,26-27]. From public healthcare center to tertiary hospitals compete with each other to attract patients with primary care sensitive condition [28-29]. However, there has been no attempt to apply PCAT to all medical institutions. Such studies are necessary because local clinics are not the only medical institutions that provide diverse primary care services. Given this context, this study aimed to assess the strengths and weaknesses of the primary care services that were provided by the three types of medical institutions.

We found that the total scores on the KPCAT were similar for local clinics and general hospitals, but they were slightly lower for tertiary hospitals. However, domain-wise analyses revealed more complex patterns. "First contact" was the only attribute that the score was drastically lowered as the level of the medical institution increased in the order of local clinic, general hospital, and tertiary hospital. Analyses of the subdomains revealed that the institutional differences were the widest for facility accessibility and cost appropriateness, followed by first contact utilization and basic healthcare. These trends were caused by relatively less number and more expensive cost of the upper-level institution. Although the patients felt burdened about visiting higher-level institutions, these barriers did not occlude those who wished to visit such institutions. The narrowest institutional difference emerged for the subdomain of demographic accessibility. In a past study, a very high score (96 out of 100) had emerged for this item [24]. This subdomain was originally designed to measure whether an institution is equipped to treat the general conditions of a wide range of patients. However, it can also be interpreted as the question for special conditions suitable for the upper-level institution. In addition, South Korea has adopted the "mandatory designation system," whereby all authorized medical institutions were automatically contracted with a single insurer; thus, they cannot refuse treatment to any patient without providing a legally valid reason. Such a situation in South Korea would have resulted in a relatively high score with less deviation.

In contradistinction to the trends that emerged for the first contact domain, the lowest scores on the other four domains emerged for local clinics. Theoretically, if the primary care works well, not only the overall scores for all domains are high, but also local clinic gets the highest score among the three levels of medical institution. Therefore, these results are showing the dysfunction of primary care and the healthcare delivery system of South Korea. With respect to comprehensiveness and family/ community orientation, local clinics performed worse than general and tertiary hospitals did. Scores on the coordination and personalized care domains were not significantly different between local clinics and general hospitals, but the differences between local clinics and tertiary hospitals were significant. Extremely short consultations and a shortage of manpower in local clinics may 
account for these findings because these domains are generally related to labor-intensive services. In Korea, a doctor who works in a local clinic typically sees more than 50 outpatients, and there are little incentives for doctors to provide preventive counseling [30]. As a result, they cannot afford to take an interest in anything other than the chief complaint of the patient. On the other hand, general and tertiary hospitals have abundant manpower, and these professionals can provide these kinds of counseling services (i.e., instead of the doctor). Among the various areas of primary care that need to be addressed, training healthcare workers to play the role of a gatekeeper and providing incentives to primary care providers whose patients witness excellent outcomes should be the highest priority in order to facilitate an improvement in healthcare quality [26].

This study has some limitations. First, there is a possibility of participant bias because our participants were asked to participate freely according to their will. Second, quota sampling was used, but characteristics other than age, sex, and residence were not used for stratification. Therefore, there is potential for systematic sampling error. Third, the order in which the medical institutions were presented in the survey questionnaire may have influenced the results because people tend to feel fatigued as the survey progresses and, consequently, they may roughly answer. Finally, participants were included in the sample, irrespective of their past experiences of visiting the three types of medical institutions; therefore, some of their answers may be based on their perceptions rather than their experiences. Notwithstanding these limitations, this study is significant because it used the KPCAT to various levels of medical institution which take a role in primary care service. Further research is needed to examine the relationships between scores on the KPCAT and outcome measure of primary care.

In conclusion, local clinics are generally perceived to be medical institutions that are responsible for providing primary care, but only one domain (i.e., first contact) of their primary care performance (i.e., assessed using the KPCAT) was superior to that of the other medical institutions. National efforts should be taken to improve their performance in the other four domains. This can be accomplished by training the workforce and providing appropriate incentives. This will strengthen the role that local clinics play as primary care providers within the healthcare system in South Korea.

\section{$\vee$. References}

1. How Health Care Is Organized? In: Bodenheimer T, Grumbach K, editors. Understanding Health Policy: A Clinical Approach. 7th edition [Internet]. New York: McGraw-Hill; 2016 [cited 2019 July 3]. Available from: https://accessmedicine.mhmedical. com/content. aspx?bookid=1790\&sectionid=121191474 Accessed.

2. Shi L, Macinko J, Starfield B, Wulu J, Regan J, Politzer, R. The relationship between primary care, income inequality, and mortality in US States, 1980-1995Journal of the American Board of Family Medicine. 2003;16:412-22.

3. Cebul RD, Rebitzer JB, Taylor LJ, Votruba ME. Organizational fragmentation and care quality in the US healthcare system. Journal of Economic Perspectives. 2008;22:93-113. 
4. Kumar S, Ghildayal NS, Shah RN. Examining quality and efficiency of the US healthcare system. International Journal of Health Care Quality Assurance. 2011;24:366-88.

5. Song YJ. The South Korean health care system. Japan Medical Association Journal. 2009;52:206-9.

6. Chun CB, Kim SY, Lee JY, Lee SY. Republic of Korea: Health system review. Health Systems in Transition. 2009;11:1-184.

7. Ock M, Kim JE, Jo MW, Lee HJ, Kim HJ, Lee JY. Perceptions of primary care in Korea: a comparison of patient and physician focus group discussions. BMC Family Practice. 2014;15:178.

8. Jung H, Jo MW, Kim HJ, Jang WM, Eun SJ, Lee JY. General public's perspectives on medical doctors and local clinics in South Korea. International Journal of Environmental Research and Public Health. 2019;16:2030.

9. Kim A, Cho S, Kim H, Jung H, Jo MW, Lee JY, et al. Primary care patients' preference for hospitals over clinics in Korea. International Journal of Environmental Research and Public Health. 2018;15:1119.

10. Dourgnon P, Naiditch M. The preferred doctor scheme: a political reading of a French experiment of gate-keeping. Health Policy. 2010;94:12934.

11. McClellan M, McKethan AN, Lewis JL, Roski J, Fisher ES. A national strategy to put accountable care into practice. Health Affairs. 2010;29:982990.

12. Wu TY, Majeed A, Kuo KN. An overview of the healthcare system in Taiwan. London Journal of Primary Care. 2010;3:115-9.

13. Ikegami N. Achieving universal health coverage by focusing on primary care in Japan: lessons for low-and middle-income countries. International Journal of Health Policy and Management. 2016:5:291.

14. Hoffmann K, George A, Jirovsky E, Dorner TE. Re-examining access points to the different levels of health care: a cross-sectional series in Austria. European Journal of Public Health. 2019. doi: 10.1093/eurpub/ckz050.

15. Primary care [Internet]. United States of America: American Academy of Family Physicians; c2019 [cited 2019 Jul 3]. Available from: https://www. aafp.org/about/policies/all/primary-care.html.

16. Donaldson MS, Yordy KD, Lohr KN, Vanselow NA, editors. Primary Care: America's Health in a New Era. Washington: National Academies Press; 1996.

17. Jamoulle M, Resnick M, Stichele RV, Ittoo A, Cardillo E, Vanmeerbeek M. Analysis of definitions of General Practice/Family Medicine and Primary Health Care. British Journal of General Practice. 2017;50. doi: 10.3399/bjgpopen17X101049.

18. Bodenheimer T. Coordinating care-a perilous journey through the health care system. The New England Journal of Medicine. 2008;358:1064-71.

19. Starfield B, Shi L, Macinko J. Contribution of primary care to health systems and health. The Milbank Quarterly. 2005;83:457-502.

20. Wright DR, Haaland WL, Ludman E, McCauley E, Lindenbaum J, Richardson LP. The costs and cost-effectiveness of collaborative care for adolescents with depression in primary care settings: a randomized clinical trial. JAMA Pediatrics. 2016;170:1048-54.

21. Burger A, Silima T. Sampling and sampling design. Journal of Public Administration. 2006;41:656-68.

22. Brick JM. The future of survey sampling. Public Opinion Quarterly. 2011;75:872-888. 
23. Yang K, Banamah A. Quota sampling as an alternative to probability sampling? An experimental study. Sociological Research Online. 2014;19:111.

24. Lee JH, Choi YJ, Sung NJ, Kim SY, Chung SH, Kim $J$ et al. Development of the Korean primary care assessment tool? measuring user experience: tests of data quality and measurement performance. International Journal for Quality in Health Care. 2009;21:103-111.

25. Lee JH, Choi YJ, Volk RJ, Kim SY, Kim YS, Park HK et al. Defining the concept of primary care in South Korea using a Delphi method. Family Medicine. 2007;39:425.

26. Organization for Economic Cooperation and Development (OECD), OECD Reviews of Health Care Quality: Korea - Raising Standards, Geneva: OECD Publishing; 2012.

27. Lee JY, Eun SJ, Kim HJ Jo MW. Finding the primary care providers in the specialist-dominant primary care setting of Korea: a cluster analysis. PloS one. 2016;11:e0161937.

28. Lee JY, Jo MW, Yoo WS, Kim HJ, Eun SJ. Evidence of a broken healthcare delivery system in Korea: unnecessary hospital outpatient utilization among patients with a single chronic disease without complications. Journal of Korean Medical Science. 2014:29:1590-96.

29. Lee JY, Jo MW, Kim HJ, Ock MS, Jung H, Eun SJ. Are the Public Health Centers Real Threats to Private Clinics in Korea?. Iranian Journal of Public Health. 2016;45:535-6.

30. Im GJ, Choi JW, Lim SM, Seo KH, Park YH. A survey of the medical practitioners' offices in Korea 2011. Journal of the Korean Medical Association. 2012;55:390-403. 